\title{
Contribuições da performance dos folguedos populares para os processos de formação do ator
}

Joana Abreu Oliveira*

O presente trabalho é parte de uma pesquisa mais ampla, desenvolvida no Mestrado em Arte da Universidade de Brasília, que pretende refletir a respeito das contribuições do fazer dos brincantes populares para os processos de formação do ator. Para a citada pesquisa de mestrado, foi escolhido como caso a ser estudado o folguedo do Bumba-meu-boi maranhense, bem como, algumas brincadeiras populares vizinhas ${ }^{1}$ a este folguedo. $\mathrm{O}$ recorte apresentado aqui tratará, especificamente, de estabelecer relações concretas entre o fazer do brincante e a formação do ator, mencionando brevemente processos de trabalho de atores, pesquisadores e grupos teatrais que, de alguma maneira, fazem interface com elementos de culturas tradicionais. Essa breve contextualização será bastante específica, já que pretende considerar principalmente casos existentes no Brasil contemporâneo. Finalmente, serão levantados alguns princípios presentes no fazer do brincante no que diz respeito, entre outras coisas, aos códigos corporais e à relação com a platéia. Tais princípios também são aplicáveis ao fazer do ator, incluindo os processos de preparação, treinamento ou formação do mesmo.

Nas últimas décadas, artistas cênicos e pesquisadores de teatro no Brasil e no mundo têm aderido à hipótese de que as culturas que possuem uma tradição de extrema codificação de suas práticas espetaculares são fonte valiosa para a formação de atores. Não raro, essa idéia de tradição coincide com os saberes das chamadas culturas populares. Vários exemplos de contribuições das tradições para o teatro mundial podem ser citados. Um deles é aquele encontrado no trabalho do ator e diretor russo Vsevolod Emilievich Meyerhold, que baseou boa parte dos princípios norteadores do seu sistema de treinamento e fundamentos para a formação e o trabalho do ator, a Biomecânica, em elementos da tradição russa, além de tradições orientais. Aquilo que, na Biomecânica, ele chamou de pré-jogo, por exemplo, baseavase na técnica dos comediantes chineses e japoneses (in HORMIGON, 1998: 86). Meyerhold dizia que é do começo das tradições que se deve retirar tudo aquilo que é indispensável para o trabalho do ator (Idem: 258). Mais ainda, ele acreditava que não havia sofrido tantas influências (que classificava como decadentes) da Europa Ocidental, por nunca ter deixado de estudar o folclore russo. Havia decidido "apoiar-se na arte do povo" (Idem: 324, tradução minha).

Como ele, Antonin Artaud foi beber na fonte do teatro tradicional balinês para criar um teatro que diferia bastante do que se fazia então na Europa Ocidental. Depois deles, diretores-pesquisadores como Berthold Brecht, Peter Brook, Jerzy Grotowski e Eugenio Barba traçaram caminhos de troca com o oriente e, em alguns casos, com as culturas tradicionais

\footnotetext{
* Mestranda em Artes (IdA-UnB). Linha de pesquisa: Processos Composicionais para a Cena, sob orientação do Prof. Dr. Fernando Pinheiro Villar. É atriz da CORTEJO cia de atores desde 1994 e aprendiz de algumas brincadeiras populares maranhenses.
} 
africana e latino americana, que foram fundamentais para o desenvolvimento de todo o seu trabalho. O Teatro Antropológico, como campo de estudo, é fruto dessa relação entre culturas.

Talvez pelo fato das culturas orientais já terem sido apontadas por referências fortes para o teatro contemporâneo, como os já citados Meyerhold, Grotowski e Artaud, estas acabaram ocupando, no Brasil, lugar muito visível quando se trata de processos e metodologias de formação de atores, quem sabe até mais visível do que aquele ocupado pelas tradições nacionais. Está claro que esse diálogo com culturas diversas é fundamental. As tradições orientais certamente foram, são e serão valiosas para nosso teatro. Contudo, é ainda mais enriquecedor, acrescentar a essas investigações a ampliação da pesquisa a respeito da maneira com que os mesmos princípios encontrados em tradições como as da China e do Japão se manifestam nos folguedos e nas festas dramáticas da cultura popular brasileira.

Uma das vantagens do contato com as manifestações brasileiras é a proximidade com mestres e comunidades que realizam brincadeiras dessa natureza. Certamente, a qualidade de aprendizado dos elementos da tradição, por sua própria natureza, está intrinsecamente ligada à vivência daquela tradição. A possibilidade de viver a experiência e criar em vivência é um dos vínculos mais contundentes entre a tradição e o teatro. Se é possível aprender o calor do jogo, da presença viva, talvez não seja interessante limitar esse aprendizado à cultura letrada ou ao contato com registros áudio-visuais, que deixam espaço mais restrito a tal experiência e que são a maneira mais viável, em nosso país, de entrar em contato com as tradições de povos de países mais distantes. Está claro que o próprio fazer teatral oferece tal experiência, mas os saberes são construídos de forma mais consistente quando podemos aplicar um mesmo tipo de hipótese a situações distintas.

No Brasil, trabalhos como os dos grupos Lume, em Campinas, Piolin, na Paraíba; e de artistas como Antônio Nóbrega e Élder Vasconcelos, em Pernambuco, e outros menos conhecidos, mas não menos consistentes, partem de princípios bem semelhantes. Mais recentemente, começam a aparecer resultados de pesquisas acadêmicas que relacionam saberes tradicionais populares ao fazer do ator e do artista cênico em geral. É o caso de pesquisadores e professores que realizam suas próprias investigações e orientam trabalhos de alunos nessa direção, como Beti Rabetti (UNIRIO), Zeca Ligiéro (UNIRIO), Eliene Benício (UFBA), Oswald Barroso (Ceará), Inês Alcaraz Marocco (UFRGS), Isa Trigo (UnEB), além de investigadores da área da dança, como Ciane Fernandes (UFBA), Graziella Rodrigues (UNICAMP) e Regina Pollo Müller (UNICAMP), apenas para mencionar alguns.

É possível citar ainda buscas mais antigas, como a que foi desenvolvida nos anos 1940, em Pernambuco, pelo Movimento Armorial, em seu Teatro do Estudante Pernambucano (TEP), que trazia entre seus integrantes figuras como Ariano Suassuna e Hermilo Borba Filho. Segundo Idellete Muzart Fonseca dos Santos, "o principal compromisso do TEP, no plano literário e teatral, é com a cultura popular nordestina. E o primeiro trabalho realizado é uma pesquisa, uma descoberta atenta e apaixonada da poesia e dos artistas populares" (SANTOS, 1999: 39).

No entanto, embora já haja caminhos dessa natureza trilhados na área do teatro, as investigações sobre as contribuições de fazeres tradicionais populares brasileiros para a 
arte do ator ainda podem ser bastante aprofundadas. Identificar princípios pilares comuns a esses dois universos pode ser um caminho de aprofundamento da consciência das possíveis contribuições desse encontro.

\section{O Bumba-meu-boi e sua vizinhança}

Serão tomados, a partir daqui, alguns exemplos de princípios presentes no folguedo brasileiro do Bumba-meu-boi, da forma com que é brincado no estado do Maranhão e em algumas brincadeiras vizinhas à do Boi. No âmbito deste artigo, serão consideradas brincadeiras vizinhas à do Bumba-meu-boi aquelas que também são praticadas pelas comunidades que brincam o Boi, como é o caso do Tambor de Crioula, do Caroço e do Cacuriá. Essas outras brincadeiras, muitas vezes, são freqüentadas por alguns brincantes de Boi individualmente. Esses indivíduos, ao transitarem pelas diversas brincadeiras, acabam por contribuir para o intercâmbio de elementos entre as mesmas. Sendo assim, essa característica de vizinhança não se dá somente por proximidade geográfica ou por coincidência de brincantes, mas principalmente por haver entre as brincadeiras um intercâmbio, um ir e vir de elementos que vão possibilitando que umas influenciem e transformem às outras, num espaço liminar, um entremundo. Há então uma espécie de zona de contágio, de vizinhança, na qual uma pode devir-outra, continuando a ser a mesma (FERRACINI, 2004: 194).

É importante ressaltar que os princípios que serão citados também podem ser encontrados em muitos outros folguedos, bem como em tradições de outros países, tendo o Boi e sua vizinhança sido escolhidos para contribuir com exemplos para a presente reflexão por estarem presentes na trajetória da própria pesquisadora. Apenas para localizar o leitor no contexto de cada um dos citados folguedos, será feita uma breve descrição de cada um, ressaltando que para de fato oferecer um panorama adequado sobre as brincadeiras seria necessário detalhá-las e refletir sobre muitos aspectos de sua natureza, o que não caberia neste trabalho, com seus objetivos específicos.

As festas, brincadeiras e rituais populares estão muitas vezes relacionados, na história da humanidade, com os ciclos da natureza e os períodos de equinócio e solstício. A festa de São João, por exemplo, coincide com o solstício de verão no hemisfério norte, onde, a fim de homenagear o Deus Sol, acendiam-se várias fogueiras que, segundo nos conta Sir Richard Burton, na Antologia do Folclore Brasileiro, de Luís da Câmara Cascudo, eram uma homenagem ao mundi animus, ou seja, à luz solar (CASCUDO, 2001: 147). Dentre essas festas e rituais extremamente difundidas ao longo dos tempos e das regiões do planeta, estão aquelas que giram em torno da figura do boi, figura que está ligada a odes e celebrações, a sacrifícios e louvores. No Brasil, é possível encontrar a brincadeira do boi espalhada por diversas partes do país, tais como, Amazonas e Pará (Boi-bumbá), São Paulo (Boi de Jacá), Rio Grande do Sul (Boizinho), Paraná e Santa Catarina (Boi-de-mamão), Ceará (Boi Surubim), Espírito Santo (Boi de Reis ou Reis de Boi), Bahia (Boi duro ou Boi de Reis), Minas Gerais (Mulinha ou Boi da Mata), Mato Grosso (Bois-à-Serra), Rio de Janeiro (Boi-Pintadinho), Piauí, Pernambuco,

além de outras Regiões do Nordeste (Boi Calemba) e do próprio Maranhão (Bumba-meu- 
boi), e assim por diante. A época de realização da brincadeira é, em alguns lugares, o Ciclo Junino e, em outros, o Ciclo Natalino.

Como em qualquer região do país, no Maranhão, a brincadeira foi encontrando seus contornos próprios, ganhando características específicas da situação sócio-cultural em que esteve inserida ao longo de sua história. Lá a brincadeira do Boi ocorre nos festejos do Ciclo Junino ou Joanino (que compreende as festas de Santo Antônio, São João, São Pedro e São Marçal), no período de junho a agosto. Nessa época, os grupos de Boi costumam levar aos arraiás música, dança e encenação. Essa encenação é chamada, pelos próprios participantes da brincadeira, de "comédia". A encenação da comédia, que também é conhecida como Auto ou matança, gira sempre em torno da figura do boi, mas traz personagens fixos como o Amo, o Contra Amo, o Pajé, o Vaqueiro, Pai Francisco e Catirina. As toadas têm uma seqüência específica: Guarnicê, Lá vai, Licença, Saudação, Urrou, Despedida. ${ }^{2}$ Não que as melodias ou letras se repitam. Cada grupo compõe suas toadas, que são inéditas a cada ano. Contudo, as novas temáticas são geralmente inseridas na citada seqüência. Dentro dessa ordem, muitas vezes, as letras das toadas falam sobre questões atuais do universo da comunidade que realiza a brincadeira, trazendo uma visão e um posicionamento específicos em relação a essa realidade.

Intercaladas com as toadas, são apresentadas as cenas que contam o enredo do Auto. A versão mais difundida, e talvez a mais antiga, conta uma história que se passa em uma fazenda, propriedade de um fazendeiro de muitas posses, dono de um boi muito especial que está sendo guarnecido em homenagem a São João. Vive também na fazenda um casal de empregados, chamados: Pai Francisco e Mãe Catirina. Essa última está grávida e deseja comer a língua do tal boi preferido do patrão. Para evitar que seu filho nasça com cara de língua, Pai Francisco rouba o boi e foge com ele da fazenda. Ao descobrir o acontecido, o Amo manda os vaqueiros saírem em perseguição ao boi. Ao ser encontrado, Chico é castigado, e o boi, que a essas alturas já está morto, é ressuscitado pelos pajés ou pelos doutores, dependendo da versão. ${ }^{3} \mathrm{O}$ urro do boi é o sinal para que todo o povo celebre sua ressurreição. ${ }^{4}$

No entanto, nem sempre o enredo do Auto se mantém fiel a essa versão, sofrendo modificações que são impulsionadas tanto pelo motivo da promessa feita a São João (no caso dos Bois de promessa) quanto pela necessidade de inovar para atrair o público. Assim, a comédia se altera como uma forma de reação às mudanças vividas ao longo dos tempos (CARVALHO, 1995: 117).

O Tambor de Crioula, uma das brincadeiras vizinhas já mencionadas, é um folguedo que envolve música e dança, provavelmente nascido entre os escravos brasileiros. Em sua versão mais difundida, a dança acontece em uma roda formada por mulheres, vestidas com saias longas e rodadas, denominadas coreiras. Uma de cada vez, as mulheres entram no meio da roda e dançam diante dos três tambores usados para tocar a música da brincadeira. ${ }^{5} \mathrm{~A}$ troca da coreira que está no meio da roda se dá no momento em que outra coreira entra na roda e chama a primeira para a 'punga', que é uma espécie de umbigada entre as duas brincantes. Até se concretizar a umbigada, muitas vezes as duas coreiras dançam juntas e se desafiam a determinados movimentos da dança. Depois da umbigada, a primeira sai da roda e a segunda permanece até que outra coreira venha tirá-la. Toda a dança acontece direcionada 
para o tambor grande que marca o tempo da 'punga'. As toadas são sempre puxadas por um dos cantadores e respondidas pelo coro, formado tanto pelas mulheres como pelos homens. De acordo com a tradição, apenas mulheres dançam e somente homens tocam. ${ }^{6}$ Muitas vezes, a roda de tambor é feita para pagar uma promessa realizada para o santo, podendo acontecer em qualquer época do ano.

As outras duas brincadeiras abordadas aqui são derivadas do carimbó das caixeiras e estão relacionadas com uma outra festa maranhense, a Festa do Divino Espírito Santo, que é uma festa religiosa, de provável herança portuguesa, que celebra o Pentecostes. No Maranhão, a festa tem um ritual próprio, no qual uma parte extremamente importante é a presença das caixeiras, que recebem esse nome devido ao instrumento que tocam, chamado caixa (que é um tambor de duas peles, tocado com baquetas) e que conhecem todas as etapas da festa. Com seus toques e cantos, essas mulheres conduzem o andamento desse rito. Como tradicionalmente a festa durava muitos dias, havia momentos de intervalo, ou mesmo após o encerramento da festa, em que as caixeiras se reuniam para toques mais profanos, ou seja, para cantar, dançar e brincar. Desses momentos nasceu o carimbó das caixeiras que depois se derivou em outras brincadeiras. Uma delas é o Cacuriá, que foi criado, por seu Lauro, nos anos 1970, sendo brincado inicialmente pelos mesmos brincantes do grupo de Boi de Seu Lauro. ${ }^{7}$ Ao som do mesmo tipo de instrumento utilizado pelas caixeiras na Festa do Divino, o Cacuriá é uma dança circular que se dança em par. Algumas músicas têm inclusive coreografia específica. $\mathrm{O}$ Caroço, outra brincadeira derivada da Festa do Divino, está localizado principalmente na cidade de Tutóia (MA), sendo por isso conhecido como Caroço de Tutóia. Atualmente, sua guardiã mais conhecida é Dona Elza, moradora da cidade, que aprendeu com as caixeiras mais antigas de sua região. Também é uma dança circular, mas sem a ênfase nos pares. Em geral, o cantador costuma improvisar muitos versos. Os brincantes dançam e respondem o canto, formando um coro.

Após apresentar brevemente a estrutura de cada brincadeira, é possível discutir sobre alguns princípios presentes em todas elas, que também são fundamentais no fazer teatral.

\section{Princípios comuns às brincadeiras populares e ao teatro}

O primeiro princípio a ser discutido é o da Repetição que está presente em todas as etapas dos folguedos citados. Nas toadas e cantigas, por exemplo, há sempre um refrão que se repete (cantado pelo coro), que dá suporte para o improviso ou para o solo não improvisado dos cantadores. Além disso, na maior parte dos casos, não há arranjos diferenciados das músicas, sendo estas parecidas entre si (embora diferentes) e cada uma delas sem muita variação ao longo de sua execução. ${ }^{8}$ Os passos dançados e os personagens das encenações, em sua grande maioria, são os mesmos há anos, sendo repetidos por mestres e imitados por aprendizes, até que se chegue ao domínio total de cada um. No entanto, essa repetição/ imitação não elimina a individualidade de cada sujeito brincante. Luigi Pareyson ajuda a diferenciar a imitação criadora e inovadora daquela meramente repetitiva e reprodutiva:

Se é verdade que algumas vezes a tradição degenera em convencionalismo 
exterior e a imitação decai para inerte repetição, é também verdade que ou uma ou outra, no seu significado mais genuíno e positivo, implicam inovação e criatividade, ou melhor, são tais que só com a livre inovação explicam a continuidade, dando lugar a uma arte que afirma a própria originalidade, precisamente enquanto prossegue a antiga, dela retirando solicitação e alimento, e aceitando a ela ligar-se e nela inspirar-se. Aquilo que se trata de explicar é a originalidade na continuidade e a continuidade na originalidade (PAREYSON, 2001: 139).

Nesse sentido, paradoxalmente, a codificação pode deixar de ser um elemento que limita a criação e o novo para ser um trampolim que possibilita que a transformação, a originalidade e a composição aconteçam. O domínio da regra surge então como elemento fundamental para que se estabeleça o jogo.

Outros princípios presentes nas brincadeiras em questão são os da Presença, da Integração e da Interdisciplinaridade. Os três elementos estão relacionados com a idéia de brincante completo ou total. $\mathrm{O}$ aprendizado e a execução da brincadeira não se dão com a separação das áreas e técnicas que estão envolvidas no fazer do brincante. Em primeiro lugar, não se aprende ritmo, melodia, canto ou condicionamento físico como disciplinas separadas. Aprende-se o todo da brincadeira: um pouco mais a cada dia, a cada experiência vivida brincando. Em segundo lugar, grande parte dos brincantes e mestres de brincadeira desempenham funções diversas: tocam um ou vários instrumentos, cantam, dançam e representam os personagens da encenação. Em alguns casos, participam de mais de um tipo de folguedo, o que ajuda a desenvolver habilidades diversas. Soma-se a isso o fato de o brincante, muitas vezes, ter a necessidade de executar diversas atividades simultâneas, como tocar, cantar, dançar, relacionar-se com o espaço, com o outro brincante, com o público, tudo ao mesmo tempo. Essa simultaneidade exige a presença e concentração totais para que tudo isso possa funcionar harmonicamente.

A Superação dos limites do corpo também é um princípio presente nas brincadeiras e no teatro. Nos folguedos, a dança e a música acontecem ao longo de horas a fio. No caso do Tambor de Crioula, as bailantes têm idades distintas, sendo possível encontrar coreiras com mais de 80 anos capazes de dançar a noite toda. A dança inclui momentos longos de giro veloz, flexões de perna que exigem bastante dos joelhos e constante movimento de pés e quadris. No caso da coreira não ser tirada da roda, esta precisa ficar dançando até que outra venha substituí-la ou que os tambores parem de tocar. Mesmo que esse momento se prolongue muito, levando ao cansaço do corpo, a coreira não pode deixar a roda. No Bumba-meu-boi, muitos dos bailantes, além de dançar por horas a fio, carregam vestimentas pesadíssimas (especialmente os adereços de cabeça) que exigem uma resistência e entrega extras do corpo. Também há muitos movimentos de giro e de impacto para pernas e joelho. ${ }^{9}$

A crescente experiência ao longo de anos de brincadeira e a situação festiva ajudam a capacitar o corpo de cada brincante para ultrapassar tais limites. No entanto, na maioria dos casos, essa resistência é fruto também de contextos de vida que incluem trabalho braçal pesado. Muitos dos participantes, em seu cotidiano, trabalham na enxada, na estiva, lavando 
roupa etc. Por último, a festa, na grande maioria dos casos, traz o elemento da bebida alcoólica, que também é um estimulante para o corpo. No entanto, nem todos os brincantes utilizam tal recurso, sendo, ainda assim, capazes da mesma resistência. As brincadeiras de Caroço também podem durar horas. Além disso, como essas brincadeiras são vizinhas, não é raro observar brincantes saírem de uma e imediatamente depois emendarem a outra, principalmente nas épocas festivas, como é o caso do São João.

Outro princípio recorrente é a Relação com o espaço. Em geral, as brincadeiras pressupõem que o participante aprenda a se relacionar com o espaço definido para o brinquedo (jogo), a deslocar-se dentro dele e a jogar com os limites desse mesmo espaço. No caso do Tambor de Crioula, por exemplo, em que o espaço é mais restrito, além de fazer sua evolução pelo espaço interno da roda, sempre em relação com o tambor grande, a coreira precisa também se relacionar com o limite formado pelo círculo em que estão as outras coreiras, de onde sairá aquela que irá interagir diretamente com ela. No caso do Boi, há um desenho no espaço para cada grupo de figuras. As índias, por exemplo, realizam seus passos e sua evolução sempre em grupo, deslocando-se por todo espaço da brincadeira. Ao mesmo tempo, o boi e seus vaqueiros também circulam por esse espaço, com outros passos e outra dinâmica. Outras figuras também fazem isso, que tem que acontecer de maneira harmônica. Além disso, em grande parte dos folguedos populares, há uma clara definição do espaço de jogo, muitas vezes feita pela roda, pelo 'cordão' de bailantes ou por figuras que vão abrindo caminho no meio do público. ${ }^{10} \mathrm{O}$ Cacuriá, que traz passos coreografados, realiza diversas evoluções espaciais, em pares, em roda, em fila, ou simultaneamente em mais de uma dessas maneiras. Finalmente, o fato de a brincadeira geralmente acontecer na rua cria elementos de risco, de variação, a partir dos quais a ação do brincante vai se aperfeiçoando.

A Relação entre a base do corpo no chão (pés, pernas, quadril) e a agilidade de movimento é outro princípio encontrado nas brincadeiras que pode ser extremamente útil ao trabalho de ator. Nos folguedos citados aqui como exemplo, para que o corpo seja capaz de deslocarse pelo espaço em situação de brincadeira durante tanto tempo, é possível observar que os brincantes possuem base firme proporcionada pela forma com que pés, joelhos e quadris se posicionam. O pé e os joelhos, na maioria das vezes, firmam o corpo em direção ao chão. No Tambor de Crioula, por exemplo, é possível perceber que as coreiras mais experientes dançam com o pé inteiro tocando o chão e com os joelhos levemente flexionados, de modo que a base permanece firme e possibilita inclusive os movimentos velozes como o giro. No Bumba-meu-boi, é possível perceber que a evolução de pés e pernas é o que define a diferença na movimentação de cada figura. No caso do quadril, este é o eixo do movimento. Percebese isso claramente no Tambor de Crioula, onde as coreiras mantêm sempre um movimento quase imperceptível do quadril ao mesmo tempo em que esse ajuda a manter o tronco ereto e íntegro, de maneira que há um eixo fixo que dá a impressão de deslizar quase imóvel sobre pernas e quadril. As brincadeiras de Caroço e Cacuriá também trazem momentos claros em que os brincantes, sem parar de dançar, alternam o corpo em pé, com a posição agachada, o que exige bastante das pernas, pés e joelhos.

Outro princípio que vale mencionar é a Relação especial com a temporalidade. O folguedo popular se localiza num tempo extremamente diverso daquele tempo vivido no cotidiano 
dos integrantes da brincadeira. Para que a festa seja realizada, todas as outras atividades são suspensas. Os participantes lançam-se a tarefas distintas daquelas realizadas no dia a dia. Ou mesmo quando a atividade é semelhante ao que se faz diariamente (como cozinhar, por exemplo), esta se reveste de outro significado, quase como se fosse outra atividade. Entretanto, há outro traço dessa temporalidade distinta que deve ser ressaltado. As festas são realizadas de acordo com um determinado calendário, repetindo-se de tempos em tempos. "No entanto, a festa que retorna não é uma outra nem a mera reminiscência de algo festejado na sua origem", sendo a experiência do tempo no folguedo "a comemoração, que é um presente sui generis" (GADAMER, 1997: 204). A palavra comemoração sugere também a idéia daquilo que pode ser memorado ou recordado em conjunto. Regularmente, determinado grupo social rememora os códigos e a essência da brincadeira. No entanto,

a cada vez que ocorre, a festa vai se modificando. Pois sempre algo diverso é simultâneo com ela. Mesmo assim, sob esse aspecto histórico, continuará sendo uma e a mesma festa, que vai sofrendo tais mudanças. Na sua origem, era assim e era festejada de uma maneira, depois foi diferente, mais tarde novamente diferente [...além disso...] deve-se à sua origem (...) que seja comemorada regularmente de acordo com a sua própria natureza original, que ela seja sempre diferente (ainda que seja celebrada 'exatamente assim') [...ou seja...] só possui seu ser no devir e o retornar" (GADAMER, 1997: 204 - 5).

Nesse sentido, é possivel estabelecer clara relação entre a festividade e a performance teatral, que pode ser repetida e extremamente codificada e, no entanto, nunca é a mesma.

Um último princípio comum a ser mencionado neste trabalho seria a Relação com o outro e o improviso. A brincadeira popular pressupõe sempre a relação entre os brincantes, seja na dança, na encenação, no jogo entre bailante e tocador. $O$ já mencionado momento em que uma coreira desafia a outra com movimentos diversos antes da 'punga', é um exemplo disso. Há ainda a relação com aqueles que acompanham 'de fora', a platéia, que algumas vezes são desafiados diretamente e outras indiretamente a permanecer com a brincadeira. A presença dessa relação cria para o brincante a possibilidade de aprendizado da própria situação de jogo com o outro. A festa tem tal estrutura em que não há essa divisão entre aqueles que fazem e aqueles que assistem. Bakhtin confirma isso quando fala do caso do carnaval: "Os espectadores não assistem ao carnaval, eles o vivem, uma vez que o carnaval pela sua própria natureza existe para todo o povo" (BAKHTIN, 1996: 6). Esse elemento é mais um ponto de ligação com o teatro se pensarmos no espectador a partir da colocação de Gadamer:

..o ser do espectador é determinado pelo seu "tomar parte" (Dabeisen). Tomar-parte é mais que mera co-presença com alguma outra coisa que lá está concomitantemente. Tomar-parte significa participação. Quem tomou parte em alguma coisa tem conhecimento de conjunto sobre como foi realmente. Somente num sentido derivado é que tomar-parte também 
significa uma forma do comportamento subjetivo, ou seja, "dedicar-se à coisa”. Assistir é, pois, uma genuína forma de participação (GADAMER, 1997: 206).

Estar em relação com os outros brincantes e com os espectadores que participam da brincadeira cria o risco da novidade, do jogo em si. O fato da brincadeira ser codificada, possuindo suas regras repetidas de geração em geração, liberta o brincante para de fato brincar. Quando o artista ganha maestria nas regras de seu fazer, pode criar. Novamente, é possível encontrar ligações com a performance teatral.

\section{Conclusão}

Esses citados acima são apenas alguns princípios, ainda superficialmente descritos e observados, mas que se aproximam muito de fundamentos buscados na formação do ator. Muitos deles aparecem nas metodologias baseadas nas tradições orientais, mas como é possível perceber, encontram correspondentes nas tradições brasileiras. Recentemente, em fala proferida em uma banca de qualificação de mestrado na Universidade de Brasília, o ator Renato Ferracini, que integra o grupo LUME, comentou observar, na trajetória de seu grupo de teatro, um movimento que partiu do uso de elementos das tradições orientais codificadas, para aproximar-se cada vez mais da investigação desses mesmos elementos nas tradições espetaculares brasileiras. ${ }^{11}$

Certamente, trabalhar com danças, cantos, toques e brincadeiras populares pode contribuir para o estabelecimento de práticas de aquecimento corporal de atores ou ainda para que esses ampliem suas habilidades técnicas no que diz respeito ao canto, à execução musical, entre outros. É provável também que tal contato possa ser espaço para a coleta de matrizes corporais e vocais que servirão a processos composição de atores ou encenação e montagem teatral. Tudo isso já vem sendo investigado por artistas como os mencionados na introdução deste texto e ainda pode ser ampliado e aprofundado. Todavia, o que este artigo propõe é que a interface com os elementos das brincadeiras populares pode ser ainda mais abrangente, possibilitando uma maior consciência do próprio fazer teatral, contribuindo para o estabelecimento de conexões entre o todo desse universo e as partes que o integram, e principalmente, constituindo-se rica fonte de busca para o ator.

\section{Notas}

\footnotetext{
${ }^{1} \mathrm{O}$ conceito de vizinhança, na forma com que é entendido neste contexto, será explicado a seguir.

${ }^{2}$ Esta ordem de toadas é citada pelo historiador e folclorista maranhense Carlos de Lima, no artigo O universo do Bumba-meu-boi do Maranhão, in NUNES, Izaurina (org.). Olhar, memória e reflexões sobre a gente do Maranhão. São Luís: CMF, 2003.

3 Há também brincantes que não admitem a morte e ressurreição do Boi, acreditando que apenas Jesus Cristo morreu e ressuscitou. Nesses casos, o Boi fica doente e acaba sendo curado pelos mesmos personagens citados acima.
} 
${ }^{4}$ Como a brincadeira do Boi está espalhada por todo o interior do estado, torna-se delicada a generalização no que se refere à ordem de toadas, cenas e mesmo à temática e presença da comédia. No entanto, a descrição acima traz o formato mais difundido atualmente, bem como classificações que se aplicam provavelmente à capital do Estado e aos municípios do interior com graus menores ou maiores de intercâmbio direto ou indireto com a capital.

${ }^{5}$ Geralmente os tambores são chamados de crivador, meião e tambor grande.

${ }^{6}$ Essa é a estrutura mais comum, mas há notícias de tambores dançados por homens (também conhecidos como Tambor de Pernada), bem como de mulheres que tocam o tambor.

${ }^{7}$ Alauriano Campos de Almeida, dono do Boi Mimo de São João, de sotaque de zabumba, tem sua sede no bairro Ivar Saldanha, em São Luís (MA).

${ }^{8}$ No caso do Tambor de crioula, por exemplo, o toque dos tambores é o mesmo para todas as toadas.

${ }^{9}$ Os passos dançados, no caso do Boi, dependem do personagem a que pertencem.

${ }^{10}$ Esse é o caso, por exemplo, dos palhaços das Folias de Reis ou dos Caboclos de Lança do Cavalo Marinho.

\section{Bibliografia}

BAKHTIN, Mikhail. A cultura popular na idade média e no renascimento. Tradução: Yara Frateschi. Brasília: EdUnB, 1993, 6.

CARVAlHO, Maria Michol Pinho de. Matracas que desafiam o tempo: é o bumba-meu-boi do Maranhão. São Luís: [s. n.], $1995,117$.

CASCUDO, Luís da Câmara. Antologia do Folclore Brasileiro. São Paulo: Global, 2001, 147.

FERRACINI, Renato. Corpos em criação, café e queijo. Tese de Doutorado apresentada no Instituto de Artes da Universidade Estadual de Campinas em 2004 (ainda não publicada), 194.

GADAMER, Hans-Georg. Verdade e método - traços fundamentais de uma hermenêutica filosófica. Tradução: Flávio Paulo Meurer. Petrópolis: Vozes, 1997, 204 - 205.

HORMIGON, Juan Antonio de. Meyerhold: Textos Teoricos. Tradução: J. Delgado, V. Cazcarra, J. L. Bello, José Fernández. Madrid: Publicaciones de la Asociación de Directores de Escena de España, 1998, 86 e 324.

PAREYSON, Luigi. Os problemas da Estética. Tradução: Maria Helena Nery Garcez. São Paulo: Martins Fontes, 2001,139.

SANTOS, Idelette Muzart Fonseca dos. Em demanda da poética popular - Ariano Suassuna e o Movimento Armorial. Campinas: Editora da Unicamp, 1999, 39. 